\title{
Auf die Spuren der rätselhaften Lehrbuchlisten: was zeigen die Zahlen uns darin?
}

\author{
Krisztina SEBESTYÉN \\ Doktoratsprogramm für Erziehungs- und Bildungswissenschaften \\ Doktorschule für Humanwissenschaften \\ Universität Debrecen \\ kriszti.se@gmail.com
}

\begin{abstract}
Abstrakt: Heutzutage ist es immer mehr keine Wahl, sondern eine Pflicht Fremdsprachen zu kennen. Die Schüler lernen meistens mehrere Sprachen in den Grund- sowie Mittelschulen, deshalb ist es nicht egal, was für Lehrbücher dazu benutzt werden. Das Ziel dieses Beitrags ist die Vorstellung der Angaben von den ungarischen offiziellen Lehrbuchlisten in den letzten 17 Jahren. Diese Listen enthalten nicht nur Lehrbücher, sondern auch Arbeitsbücher und auch weitere Ausfertigungen. Diese Forschung beschäftigt sich unter anderem mit den Verlagen, mit dem Anteil der deutsch- sowie ungarischmuttersprachigen Autoren. Die Ergebnisse zeigen die Veränderung des Angebotes während des analysierten Zeitraums, und diese Angaben von den Lehrbüchern „Deutsch als Fremdsprache” können auch zu weiteren, internationalen Vergleichen führen.
\end{abstract}

Schlüsselwörter: Lehrbücher, Statistiken, Verlage, offizielle Lehrbuchlisten

\begin{abstract}
Nowadays knowing foreign languages is a must. The children learn more languages at the school, so it does not matter what kind of books they use. The aim of our paper is to present the data of the Hungarian official list of textbooks from the last 17 years. The lists contain textbooks, exercise books and other things. This survey is about the publishers, the rate of the authors with presumed to be German and Hungarian native speakers. The results show that the change of the textbooks 'German as foreign language' and these results can lead to other international comparisons.
\end{abstract}

Keywords: schoolbooks, statistics, publishers, official lists of textbooks

\section{Einleitung und fachliterarischer Hintergrund}

Die Wichtigkeit des Fremdsprachenlernens in der Welt ist keine Frage mehr. Nach der Kommission der Europäischen Gemeinschaften ist ein Ziel beim 
Fremdsprachenlernen, dass jeder Mensch in der näheren Zukunft mindestens drei Sprachen kennen soll. Neben der Muttersprache bedeutet das noch zwei anderen Sprachen (Kommission der Europäischen Gemeinschaften 2005; Hesse-Göbel-Hartig 2008). Aber man kann jeden Tag eine Tendenz der Wichtigkeit von Fremdsprachen sehen, wenn man sich zum Beispiel um ein Stipendium oder einen Arbeitsplatz bewirbt, braucht man auch Fremdsprachenkenntnisse (vgl. Imre 2015).

Nach dem politischen Wandel darf man nicht mehr nur Russisch, sondern die sogenannten westlichen Fremdsprachen in den Schulen lernen. Deutsch ist heute nach dem Englischen die zweitpopulärste Fremdsprache in Ungarn, aber es gibt immer weniger Leute, die diese Sprache als Fremdsprache erlernen möchten. In Verbindung anderer Stundenzahlen lässt sich sagen, dass die Zahlen der Fremdsprachenstunden in Ungarn höher sind (Vágó-Simon-Vass 2011), aber die Fremdsprachenkenntnisse sind nicht die besten. Ein möglicher Grund dafür kann die Qualität und die Gestaltung verschiedener Lehrmittel sowie Lehrbücher sein. Die Lehrbücher sind nämlich nicht nur in der Schule, sondern auch bei den Sprachkursen die populärsten Lehrmittel, aber es ist sehr schwer ein Entsprechendes zu wählen (Zalánné Szablyár-Petneki 1997). Seit den 1990er Jahren wurden immer mehr Lehrwerke nicht nur in Ungarn herausgegeben, sondern auch vom Ausland importiert (vgl. Fábián 2003). Deshalb ist es wichtig, die verschiedenen Lehrbuchlisten zu analysieren, um zu sehen, welche Tendenzen man unter den Fremdsprachenbüchern während der Jahre entdecken kann.

Die offiziellen Lehrbuchlisten wurden im Jahre 1998 „gegründet“, als die Verordnung MKM 5/1998 (II.18.) in Geltung getreten ist. Diese Verordnung sprach die Bestimmung ein Buch als Lehrbuch aus und es ordnet noch heutzutage auch die Bestellung der Lehrbücher. Man soll noch das Gesetz XXXVII aus dem Jahr 2001 in Ansicht nehmen, worin um die Ordnung des Lehrbuchmarkts geht, und noch die 23/2004 (VIII. 27.) Verordnung OM über die Lehrbuchzulassung, Lehrbuchunterstützung bzw. die Lehrbuchversorgung der Schulen. Beide wurden seitdem mehrmals verändert. Im Jahre 2011 ist ein neues Erziehungsgesetz, das Gesetz CXC in Geltung getreten, und das Gesetz CCXXXII über die Versorgung mit Lehrbüchern gehört seit 2013 auch zu diesem Thema. Letztlich soll man die Verordnung EMMI 17/2014 (III. 12.) erwähnen, die auch um die Bestimmungen der Bücher als Lehrbuch behandelt. Diese Gesetze sowie Verordnungen bestimmen, anhand welcher inhaltlichen und formalen Kriterien ein Buch als Lehrbuch zugelassen werden kann, und wie es möglich ist, die Lehrbücher verbreiten zu können (Radó 2010). Die Zulassung eines Lehrwerkes dauert fünf Jahre, und das Ministerium EMMI veröffentlicht jedes Jahr die minimalen und maximalen Preise der Lehrwerke (Fehér könyv 2012-2018).

Es gibt nicht so viele Beiträge - zum Beispiel Fehérvári 2000; Petneki 2002; Radó 2010 -, die sich mit dem Lehrbuchmarkt, der Menge und den Typen der 
Lehrwerke und der Verlage usw. beschäftigen. Deshalb geht es in diesem Aufsatz um die ungarischen Lehrbuchlisten zwischen den Schuljahren 1998/1999 und 2014/2015. Offizielle Datenbanken und Analysen sind nur in wenigen Ländern erreichbar (Pingel 2010), deshalb wurde jetzt eine Datenbank aus diesen offiziellen Lehrbuchlisten gestaltet und analysiert. Aus diesen Lehrbuchlisten werden jetzt nur die Lehrwerke „Deutsch als Fremdsprache“ analysiert.

\section{Datenbank und Methoden}

Mithilfe der Analyse von den offiziellen Lehrbuchlisten kann man die zwischen den Schuljahren 199/1999 und 2014/2015 erschienenen Lehr- und Lernmöglichkeiten der deutschen Sprache in Ungarn durchschauen. Unsere Datenbank besteht aus diesen 17 offiziellen Lehrbuchlisten. Diese Listen enthalten nicht nur Lehrbücher, sondern auch Arbeitsbücher und weitere Ausfertigungen: Klassenarbeiten, Hausaufgabenhefte, Hörtexte, Teste und Aufgaben für Sprachprüfungen und Abitur, Wörterbücher und Glossare, Wortschatzproben, Übersetzungsaufgaben. Es gab früher auch Kassetten, heutzutage lieber CD-s zu einigen Lehrwerken. Diese Lehrwerke bilden oft Lehrbuchfamilien sowie Lehrbuchreihen (Karlovitz J. 2001; Radó 2010). Es werden verschiedene Merkmale von Büchern in diesen Lehrbuchlisten veröffentlicht. In den meisten Fällen sind die Namen der Autoren, der Titel, die Verlagskode, die Satelliten der Lehrwerke, der Namen der Verlage, das Gewicht, der Preis, sowie die Gültigkeit der Bücher als Lehrbuch angegeben. In den Lehrbuchlisten bekommt man noch Empfehlungen in der Hinsicht des Jahrgangs und der Schultypen.

In diesem Aufsatz befinden sich einige beschreibenden Statistiken über die Lehrmittel, zum Beispiel haben die Autoren vermutlich ungarische oder deutsche Muttersprache, bzw. an welchem Jahrgang oder in welchem Schultyp haben die Verlage die meisten Lehrmittel. Diese statistischen Ergebnisse stammen aus unserer Datenbank, deren Analyse mit dem Statistikprogramm SPSS geschafft wurde. Die Ergebnisse wurden durch die Kreuztafeln sowie Varianzanalysen berechnet.

\section{Ergebnisse}

Mit den Daten der Lehrbuchlisten werden die Lehrwerke „Deutsch als Fremdsprache“ sowie ihre Verlage charakterisiert. Zum ersten Mal ist die Anzahl der Lehrmittel pro Schuljahr aus den offiziellen Lehrbuchlisten an der Abbildung 1 dargestellt. 


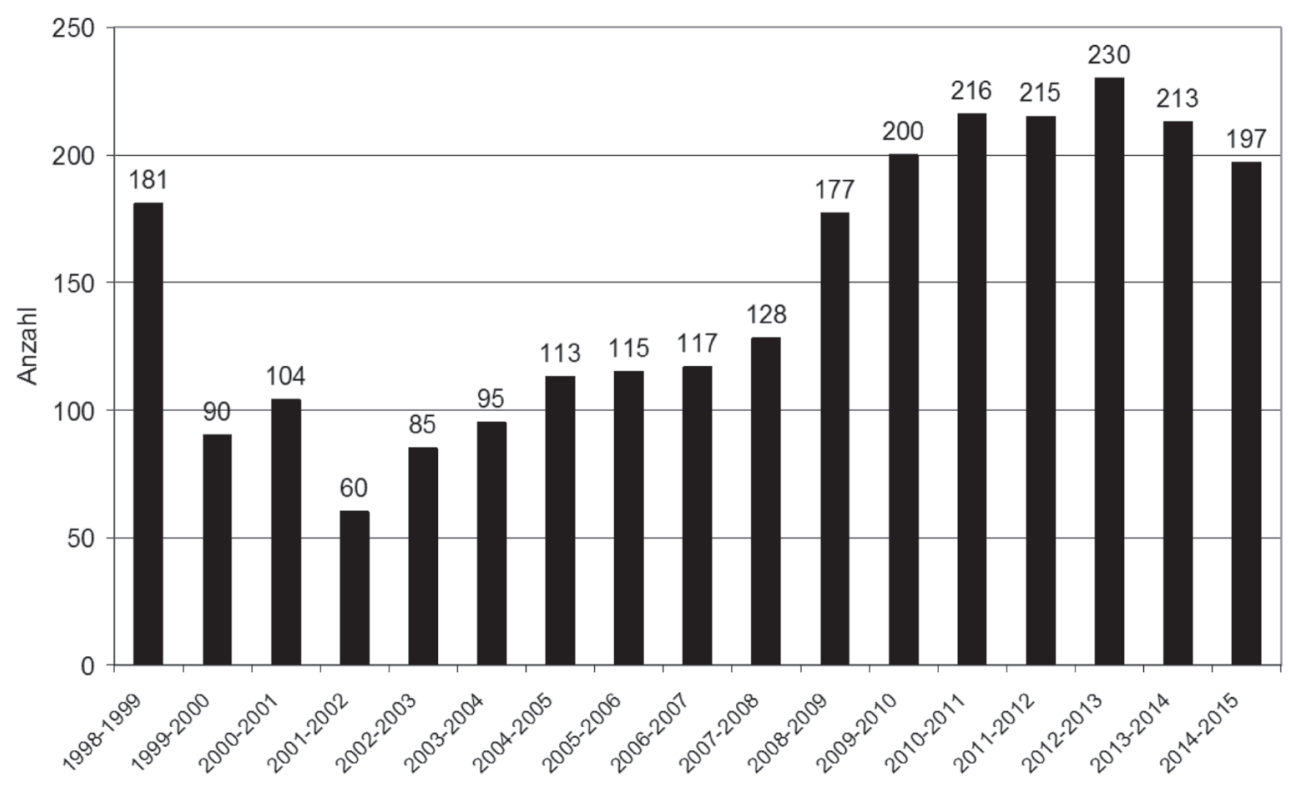

Abbildung 1. Anzahl der Lehrbücher „Deutsch als Fremdsprache“ zwischen den Schuljahren 1998/1999 und 2014/2015 (N=2536) (eigene Abbildung)

An dieser Abbildung ist es sehbar, dass es die meisten Lehrwerke „Deutsch als Fremdsprache“ im Schuljahr 2012/2013 gab. Dieses Schuljahr wird vom Schuljahr 2010/2011 und 2011/2012 gefolgt. Im Schuljahr 1998/1999 waren 181 Lehrwerke „Deutsch als Fremdsprache“ auf der offiziellen Lehrbuchliste. Es ist eine große Anzahl der Lehrmittel, aber es ist in der ersten Lehrbuchliste nach der Verordnung MKM 5/1998 (II. 18.). Danach wurden die Bedingungen und Kriterien der Zulassung als Lehrwerke wahrscheinlich verändert, deshalb sehen wir in den folgenden Schuljahren eine Verminderung der Lehrmittel. Zum Beispiel waren in dem nächsten Schuljahr 91 Stücke an der Liste, dann waren nur 60 Stücke im Schuljahr 2001/2002. Eine größere Annahme ist es im Schuljahr 2008/2009 sehbar, nach dem Schuljahr 2012/2013 ist wieder eine Verminderung zu entdecken. Die Annahme kann man damit erklären, dass die Verordnung 237/2006 (XI. 27.) 2008 in Geltung getreten ist. Vor 2008 konnte man mit einer Mittelstufeprüfung die obere Stufe vom Abitur auslösen. Mit dieser neuen Verordnung wurde diese Regel abgeschafft und es hatte zwei Ergebnisse: (1) man soll eine obere Stufe vom Abitur machen, wenn man danach im Aufnahmesystem an der Hochschule Pluspunkte bekommen möchte; (2) mit der Verordnung 237/2006 (XI. 27.) wurde die Punktzahlrechnung dieses Aufnahmesystems so verändert, dass man mehrere Pluspunkte als früher nach einer Mittelstufeprüfung bekommen kann (Sebestyén 2014). In Verbindung mit diesen Veränderungen wurden mehrere Sprachabitur- 
prüfungen zum Beispiel auch aus Deutsch gemacht und es wurde wahrscheinlich auch die Anzahl der Mittelstufeprüfungen aus den Fremdsprachen erhöht. Alles in allem lässt sich sagen, wenn der Bedarf strenger wäre, wäre auch die Zahl der Deutschlernenden vermutlich erhöht und die Lehrer brauchten auch mehrere Lehrmittel, zum Beispiel Lehrbücher. Als Verminderung des Angebots von Lehrbüchern soll man aber noch in dem analysierten Zeitraum an andere Verordnungsveränderungen denken, beziehungsweise auch an den Wirkungen der Wirtschaftskrise (Vágó-Simon-Vass 2011).

Im analysierten Zeitraum waren mehrere Verlage, die unter anderen auch Lehrbücher „Deutsch als Fremdsprache“ herausgaben. Es gibt drei Verlage - Hueber, Nemzedékek Tudása sowie Raabe Klett -, die einen oder mehrere Rechtsvorgänger hatten. Der Verlag Hueber wurde früher als Max Hueber genannt. Das heutige Nemzedékek Tudása hieß während des analysierten Zeitraums Nemzeti Tankönyvkiadó Rt., bzw. Nemzeti Tankönyvkiadó Zrt., und die Bücher von Bildungsforschungsinstitut OFI wurden auch dazu gezählt. Der heutige Raabe Klett wurde früher als Klett Könyvkiadó Kft., Klett Oktatási Tanácsadó és Kiadó Kft. und PannonKlett Könyvkiadó Kft. genannt, aber die Bücher vom Verlag Grimm werden auch dazu gezählt. In diesem Beitrag sind diese Verlage mit den heutigen Namen erwähnt, so gibt es insgesamt 25 Verlage in der Datenbank (Tabelle 1).

Tabelle 1. Verlage von Lehrbüchern „Deutsch als Fremdsprache“ zwischen den Schuljahren 1998/1999 und 2014/2015 (n=2534) (eigene Tabelle)

\begin{tabular}{lc}
\hline \multicolumn{1}{c}{ Verlage } & Anzahl \\
\hline Alfárium Szuggesztopéd Nyelvstúdió GM & 12 \\
\hline Apáczai & 82 \\
\hline Baja és Tsa Oktatási Bt. & 1 \\
\hline Corvina & 2 \\
\hline Holnap & 27 \\
\hline Homonnai és Társa & 2 \\
\hline Hueber (und ihre Rechtsvorgänger) & 596 \\
\hline Konsept-H & 17 \\
\hline Korona & 2 \\
\hline Könyvesház & 2 \\
\hline Langenscheidt & 6 \\
\hline Lexika & 164 \\
\hline Maxim & 83 \\
\hline Mozaik & 8 \\
\hline Nemzedékek Tudása (und ihre Rechtsvorgänger) & 612 \\
\hline Nordwest 2002 & 24 \\
\hline
\end{tabular}




\begin{tabular}{lc}
\hline \multicolumn{1}{c}{ Verlage } & Anzahl \\
\hline Oktatási Módszertani Kiadó & 309 \\
\hline OKTKER (NODUS) & 1 \\
\hline Oxford University Press & 18 \\
\hline Paginarium & 1 \\
\hline Pedellus N. V. & 5 \\
\hline Raabe Klett (und ihre Rechtsvorgänger) & 357 \\
\hline Romi-Suli Könyvkiadó és Továbbképző Múhely & 6 \\
\hline SZEGA BOOKS & 2 \\
\hline ZIEL & 195 \\
\hline Zusammen & $\mathbf{2 5 3 4}$ \\
\hline
\end{tabular}

Es gibt 10 Verlage, die seit dem Schuljahr 1998/1999 bis Ende des analysierten Zeitraums in jedem Schuljahr mindestens ein Lehrwerk „Deutsch als Fremdsprache“ herausgegeben haben. Diese Verlage sind die folgenden: Apáczai, Hueber, Lexika, Maxim, Nemzedékek Tudása, Nordwest 2002, Oktatási Módszertani Kiadó, Raabe Klett, SZEGA BOOKS und ZIEL. Während des analysierten Zeitraums hatte die meisten Lehrwerke der Nemzedékek Tudása (612 Stücke), dann Hueber (596 Stücke) und Raabe Klett (357 Stücke). Die Mehrheit der 25 Verlage stammt aus Ungarn, und nur vier - Hueber, Langenscheidt, Oxford University Press und Raabe Klett - aus dem Ausland. Der Verlag Nemzedékek Tudása ist der größte Verlag Ungarns, der nicht nur Sprachbücher herausgibt, und dieser Verlag hat bis heute unter den ungarischen Verlagen einen Monopolstatus (vgl. Fehérvári 2000).

Die vermutliche Muttersprache der Lehrwerkautoren kann ein Merkmal eines Sprachbuches sein, weil ein Autor mit Deutsch als Muttersprache für die Sprachlerner mehrere Sichten - zum Beispiel kulturelle oder landeskundliche Sichten einer Sprache zeigen kann. In Deutschland sind auch die Unterrichtsmethoden für Deutsch als Fremdsprache anders, das bedeutet, dass die Lehrwerke mit vermutlich deutschmuttersprachigen Autoren andere inhaltliche und methodische Gestaltung haben können. Zu diesem Merkmal wurden die Namen der Lehrwerkautoren analysiert. An der Abbildung 2 sind die 25 Verlage sichtbar, die in dem analysierten Zeitraum in Ungarn Lehrwerke „Deutsch als Fremdsprache“ herausgaben.

Die meisten Verlage haben Lehrwerkautoren mit vermutlich ungarischer Muttersprache. In 17 Verlagen werden Sprachbücher hundertprozentig mit vermutlich ungarischen Lehrwerkautoren herausgegeben. Dagegen gibt es nur zwei Verlage - Langenscheidt und Oxford University Press -, die hundertprozentig mit deutschmuttersprachlichen Lehrwerkautoren zusammenarbeiten. Der Verlag Nemzedékek Tudása sowie Nordwest 2002 sind vermutlich die ungarischen Lehrwerkautoren in Mehrheit. Voriger Verlag hat 89,42 Prozent, der andere Verlag hat 90 Prozent vermutlich ungarische Autoren. Der Verlag Holnap hat auch unga- 
rische Mehrheit unter seinen Autoren, d. h. 51,85 Prozent. Es gibt aber drei Verlage, die mehrere vermutlich deutschsprachige Autoren haben. Bei Raabe Klett ist es 80,33 Prozent, beim Maxim 80,46 Prozent und beim Hueber 94,5 Prozent. Diese letztgenannten Verlage stammen aus dem Ausland, nur der Verlag Maxim stammt aus Ungarn. Dieser Anteil ist wichtig, denn die ausländischen Verlage arbeiten mit ausländischen Autoren zusammen, und es kann in ihren Lehrwerken ausländische Methoden zum Fremdsprachenlernen geben, die in Ungarn noch nicht weit verbreitet sind (vgl. Gerighausen-Seel 1982). Ein anderer springender Punkt ist, dass die ausländischen Verlage nicht nur auf regionale Lehrwerke fokussieren, sondern auch nicht regionale Lehrwerke herausgeben. Unter den nicht regionalen Lehrwerken meinen sie die nicht landesspezifischen Lehrmittel, die in mehreren Ländern benutzt werden können (Pingel 2010; Szablyár 1995), und es kann von den ungarischen Unterrichtsmethoden abweichende Methoden bedeuten. Anhand der analysierten Lehrbuchlisten kann man also feststellen, dass die Mehrheit der Lehrwerke aus den letzten 17 Jahren in Ungarn von vermutlich Ungarisch als Muttersprache sprechenden Lehrwerkautoren stammt. Das bedeutet, die Mehrheit der Deutschlernenden lernt nach „ungarischen“ Methoden. Die Frage ist nur, ob es zwischen den ungarischen und deutschen Methoden für Deutsch als Fremdsprache einen Unterschied gibt. Das soll man noch in weiteren Forschungen analysieren.

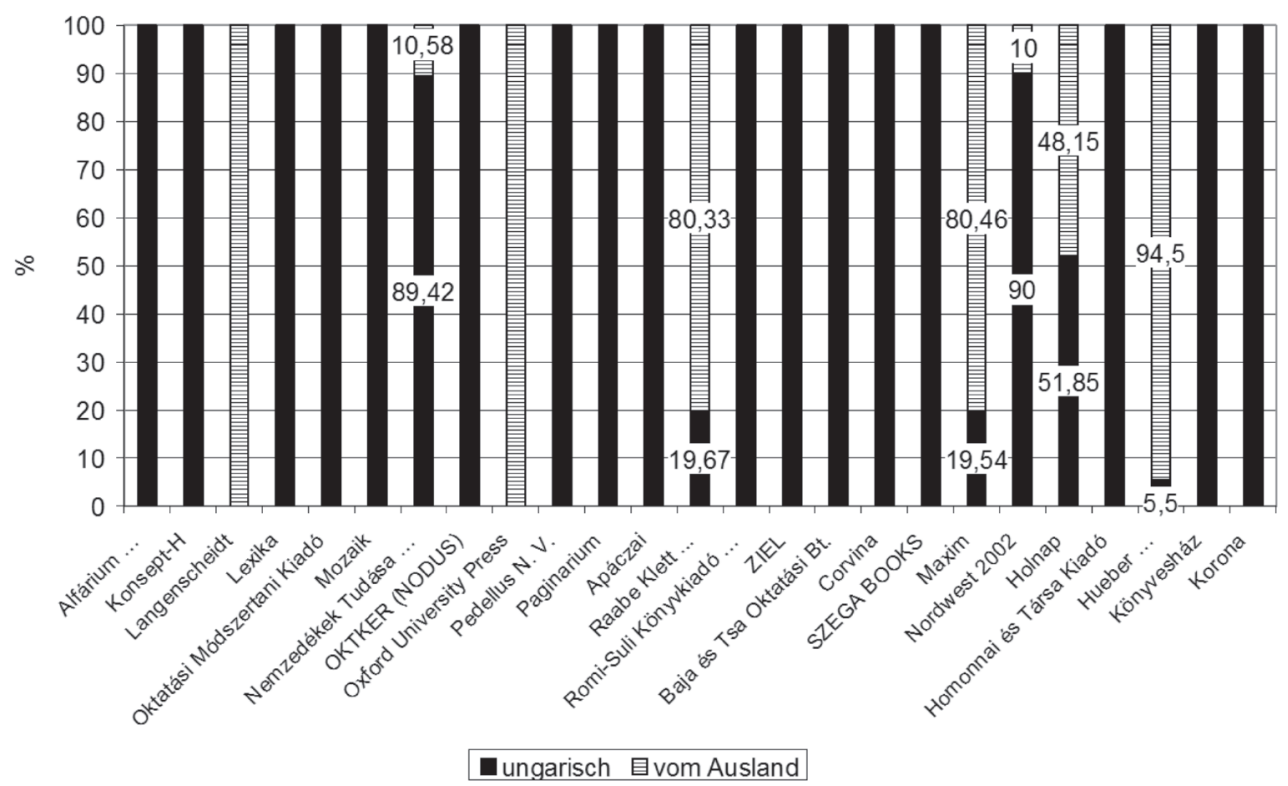

Abbildung 2. Anteil der Lehrwerkautoren mit vermutlich ungarischer und vermutlich deutscher Muttersprache (eigene Abbildung) 
Die Lehrwerke können eine Lehrbuchreihe bilden. In einer Lehrbuchreihe gibt es mehrere Lehrbücher mit ihren Satelliten, und diese Bände sind anhand innerer und äußerer Merkmalen ähnlich. Im Falle dieser Lehrbuchreihen geht es um ein Fach, und die Mitglieder der Lehrbuchreihe haben im Allgemeinen dieselbe Autorengruppe (Karlovitz J. 2001). Diese Ähnlichkeiten können die Arbeit mit dem Lehrwerk nicht nur für die Lehrer, sondern auch für die Schüler erleichtern. Es ist wichtig, weil man eine Lehrbuchreihe mehrere Schuljahre lang benutzen kann. Bei der Analyse der Lehrbuchlisten kann man feststellen, dass 60,4 Prozent der Lehrwerke zu einer Lehrbuchreihe gehören.

Eine Lehrbuchreihe hat also mehrere Lehrbücher mit verschiedenen Satelliten. Als Satelliten nennt man die Ersatzmittel - zum Beispiel Arbeitsbücher, Glossar, CD-s - eines Lehrbuchs (Karlovitz J. 2001). In den Lehrbuchlisten werden im Allgemeinen nur die Arbeitsbücher oder die Bücher für die Hausaufgaben als selbständiges Buch, ähnlich wie die Lehrbücher genannt. Die anderen Satelliten werden nur mit den Verlagskoden gezeichnet. Manchmal findet man keine weiteren Informationen über die Satelliten eines Lehrbuchs. Deshalb sind nur die Anzahl der Satelliten der einzelnen Lehrwerke sehbar (Tabelle 2).

Tabelle 2. Die Satellitenanzahl der Lehrwerke pro Verlag (n=2392) (eigene Tabelle)

\begin{tabular}{|c|c|c|c|c|c|c|c|c|c|c|c|c|c|}
\hline Verlage & $\begin{array}{c}\text { kein } \\
\text { Satellit }\end{array}$ & 1 & 2 & 3 & 4 & 5 & 6 & 7 & 8 & 9 & 10 & 15 & $\begin{array}{c}\text { Anzahl der } \\
\text { Lehrwerke, } \\
\text { die } \\
\text { Satelliten } \\
\text { haben } \\
\end{array}$ \\
\hline $\begin{array}{l}\text { Alfárium } \\
\text { Szuggesztopéd } \\
\text { Nyelvstúdió GM }\end{array}$ & 6 & 0 & 6 & 0 & 0 & 0 & 0 & 0 & 0 & 0 & 0 & 0 & 6 \\
\hline Apáczai & 13 & 31 & 32 & 3 & 0 & 0 & 0 & 0 & 0 & 0 & 0 & 0 & 66 \\
\hline $\begin{array}{l}\text { Baja és Tsa } \\
\text { Oktatási Bt. }\end{array}$ & 0 & 1 & 0 & 0 & 0 & 0 & 0 & 0 & 0 & 0 & 0 & 0 & 1 \\
\hline Corvina & 2 & 0 & 0 & 0 & 0 & 0 & 0 & 0 & 0 & 0 & 0 & 0 & 0 \\
\hline Holnap & 16 & 0 & 1 & 0 & 0 & 0 & 8 & 0 & 0 & 0 & 0 & 0 & 9 \\
\hline $\begin{array}{l}\text { Homonnai és } \\
\text { Társa }\end{array}$ & 2 & 0 & 0 & 0 & 0 & 0 & 0 & 0 & 0 & 0 & 0 & 0 & 0 \\
\hline $\begin{array}{l}\text { Hueber (und ihre } \\
\text { Rechtsvorgänger) }\end{array}$ & 129 & 20 & 22 & 133 & 133 & 104 & 19 & 20 & 0 & 0 & 0 & 0 & 451 \\
\hline Konsept-H & 3 & 14 & 0 & 0 & 0 & 0 & 0 & 0 & 0 & 0 & 0 & 0 & 14 \\
\hline Korona & 0 & 2 & 0 & 0 & 0 & 0 & 0 & 0 & 0 & 0 & 0 & 0 & 2 \\
\hline Könyvesház & 2 & 0 & 0 & 0 & 0 & 0 & 0 & 0 & 0 & 0 & 0 & 0 & 0 \\
\hline Langenscheidt & 3 & 0 & 3 & 0 & 0 & 0 & 0 & 0 & 0 & 0 & 0 & 0 & 3 \\
\hline Lexika & 43 & 11 & 2 & 55 & 1 & 39 & 5 & 0 & 0 & 0 & 0 & 2 & 115 \\
\hline
\end{tabular}




\begin{tabular}{|c|c|c|c|c|c|c|c|c|c|c|c|c|c|}
\hline Verlage & $\begin{array}{c}\text { kein } \\
\text { Satellit }\end{array}$ & 1 & 2 & 3 & 4 & 5 & 6 & 7 & 8 & 9 & 10 & 15 & $\begin{array}{c}\text { Anzahl der } \\
\text { Lehrwerke, } \\
\text { die } \\
\text { Satelliten } \\
\text { haben } \\
\end{array}$ \\
\hline Maxim & 1 & 5 & 0 & 2 & 39 & 1 & 24 & 0 & 0 & 0 & 0 & 0 & 71 \\
\hline Mozaik & 7 & 0 & 0 & 0 & 0 & 0 & 0 & 0 & 0 & 0 & 0 & 0 & 0 \\
\hline $\begin{array}{l}\text { Nemzedékek } \\
\text { Tudása (und ihre } \\
\text { Rechtsvorgänger) }\end{array}$ & 101 & 146 & 129 & 133 & 35 & 9 & 6 & 0 & 0 & 0 & 0 & 0 & 458 \\
\hline Nordwest 2002 & 0 & 12 & 12 & 0 & 0 & 0 & 0 & 0 & 0 & 0 & 0 & 0 & 24 \\
\hline $\begin{array}{l}\text { Oktatási } \\
\text { Módszertani } \\
\text { Kiadó }\end{array}$ & 78 & 58 & 11 & 1 & 4 & 102 & 45 & 0 & 0 & 0 & 0 & 0 & 221 \\
\hline $\begin{array}{l}\text { OKTKER } \\
\text { (NODUS) }\end{array}$ & 0 & 0 & 1 & 0 & 0 & 0 & 0 & 0 & 0 & 0 & 0 & 0 & 1 \\
\hline $\begin{array}{l}\text { Oxford } \\
\text { University Press }\end{array}$ & 6 & 12 & 0 & 0 & 0 & 0 & 0 & 0 & 0 & 0 & 0 & 0 & 12 \\
\hline Paginarium & 1 & 0 & 0 & 0 & 0 & 0 & 0 & 0 & 0 & 0 & 0 & 0 & 0 \\
\hline Pedellus N. V. & 5 & 0 & 0 & 0 & 0 & 0 & 0 & 0 & 0 & 0 & 0 & 0 & 0 \\
\hline $\begin{array}{l}\text { Raabe Klett } \\
\text { (und ihre } \\
\text { Rechtsvorgänger) }\end{array}$ & 50 & 74 & 21 & 32 & 53 & 3 & 36 & 6 & 8 & 40 & 3 & 0 & 276 \\
\hline $\begin{array}{l}\text { Romi-Suli } \\
\text { Könyvkiadó és } \\
\text { Továbbképző } \\
\text { Múhely }\end{array}$ & 6 & 0 & 0 & 0 & 0 & 0 & 0 & 0 & 0 & 0 & 0 & 0 & 0 \\
\hline SZEGA BOOKS & 0 & 1 & 0 & 0 & 0 & 0 & 0 & 0 & 0 & 0 & 0 & 0 & 1 \\
\hline ZIEL & 51 & 2 & 113 & 14 & 7 & 0 & 0 & 0 & 0 & 0 & 0 & 0 & 136 \\
\hline Zusammen & 525 & 389 & 353 & 373 & 272 & 258 & 143 & 26 & 8 & 40 & 3 & 2 & 1867 \\
\hline
\end{tabular}

73,68 Prozent der Lehrwerke hat nach den analysierten Lehrbuchlisten irgendwelche Satelliten. Das bedeutet in den meisten Fällen von eins bis vier Stücken. Mehr als vier Satelliten haben die Lehrwerke beim den Verlagen Holnap, Hueber, Lexika, Maxim, Nemzedékek Tudása, Oktatási Módszertani Kiadó und Raabe Klett. Die meisten Satelliten eines Lehrmittels haben die Verlage Hueber sowie Raabe Klett, aber diese Verlage benennen keine von den tatsächlichen Satelliten nur die Verlagskode der Satelliten in den Lehrbuchlisten. Wenn dieses Buch ein Mitglied einer Lehrbuchreihe ist, dann werden auch die Mitglieder einer Lehrbuchreihe als Satelliten aufgezählt. Diese Tatsache ist wichtig, wenn man über die Preise oder das Gewicht der Lehrwerke, Lehrbuchreihen nachdenkt. Im Folgenden werden die Veränderungen der Preise sowie die Veränderungen des Gewichts durchgeschaut. 
Die Preise einiger Lehrwerke verändern sich sehr schnell, solange die Preise von anderen in meisten Fällen ebensoviel bleiben. In der Tabelle 3 sind die durchschnittlichen Preise der Verlage, die Anzahl der Lehrwerke sowie die Abweichungen sehbar. Die Preisen sind im ungarischen Forint angegeben.

Tabelle 3. Durchschnittliche Preise der Lehrwerke im analysierten Zeitraum pro Verlag ( $n=2533)$ (eigene Tabelle)

\begin{tabular}{|c|c|c|c|}
\hline Verlage & $\begin{array}{c}\begin{array}{c}\text { Durchschnitt } \\
(\mathrm{HuF})\end{array} \\
\end{array}$ & $\begin{array}{l}\text { Anzahl der } \\
\text { Lehrwerke }\end{array}$ & $\begin{array}{c}\text { Abweichung } \\
\text { (HuF) }\end{array}$ \\
\hline Alfárium Szuggesztopéd Nyelvstúdió GM & 1575 & 12 & 235 \\
\hline Apáczai & 990 & 82 & 358 \\
\hline Baja és Tsa Oktatási Bt. & 445 & 1 & - \\
\hline Corvina & 865 & 2 & 120 \\
\hline Holnap & 818 & 26 & 199 \\
\hline Homonnai és Társa & 643 & 2 & 66 \\
\hline Hueber (und ihre Rechtsvorgänger) & 1794 & 596 & 582 \\
\hline Konsept-H & 2224 & 17 & 659 \\
\hline Korona & 700 & 2 & 0 \\
\hline Könyvesház & 670 & 2 & 28 \\
\hline Langenscheidt & 1690 & 6 & 397 \\
\hline Lexika & 1222 & 164 & 556 \\
\hline Maxim & 1828 & 83 & 858 \\
\hline Mozaik & 614 & 8 & 84 \\
\hline $\begin{array}{l}\text { Nemzedékek Tudása (und ihre } \\
\text { Rechtsvorgänger) }\end{array}$ & 1245 & 612 & 527 \\
\hline Nordwest 2002 & 1535 & 24 & 155 \\
\hline Oktatási Módszertani Kiadó & 612 & 309 & 262 \\
\hline OKTKER (NODUS) & 550 & 1 & - \\
\hline Oxford University Press & 1773 & 18 & 348 \\
\hline Paginarium & 1079 & 1 & - \\
\hline Pedellus N. V. & 382 & 5 & 38 \\
\hline Raabe Klett (und ihre Rechtsvorgänger) & 1593 & 357 & 439 \\
\hline $\begin{array}{l}\text { Romi-Suli Könyvkiadó és Továbbképző } \\
\text { Múhely }\end{array}$ & 720 & 6 & 263 \\
\hline SZEGA BOOKS & 1500 & 2 & 0 \\
\hline ZIEL & 790 & 195 & 501 \\
\hline Zusammen & 1324 & 2533 & 657 \\
\hline
\end{tabular}

Die teuersten Lehrbücher sind im Durchschnitt bei Konsept-H, gefolgt von Hueber, dann Oxford University Press. Es lässt sich sagen, dass die ausländischen Verlage teurer sind, aber Konsept-H, Nordwest 2002 oder SZEGA BOOKS haben auch hohe Preise. Die höchsten Abweichungen kann man auch bei den 
ungarischen Verlagen Maxim und Konsept-H entdecken. Der Dritte in dieser Reihenfolge sind die Preise des Verlags Hueber sowie sein Rechtsvorgänger. Die Veränderungen der Preise kann man mit den verschiedenen Regelveränderungen erklären, die im gegebenen Fall auf die ausländischen Verlage und Lehrwerke nicht gültig sind. Man darf aber die Veränderungen der einzelnen Lehrwerke nicht außer Acht lassen, weil die Eltern in einem Schuljahr noch andere Lehrwerke kaufen sollen. Anders gesehen, wenn der Lehrer ein Mitglied einer Lehrbuchreihe gewählt hat, sollen die Eltern wahrscheinlich mit diesem Preis in mehreren Schuljahren kalkulieren.

Der andere wichtige Punkt ist das Gewicht der Schulbücher. Die Schüler haben viele Lehrwerke, deshalb sollen die Lehrer auf das Gewicht der Lehrbücher sowie ihre Satelliten achten. Das durchschnittliche Gewicht sowie seine Abweichungen sind in der Tabelle 4 sehbar.

Tabelle 4. Durchschnittliches Gewicht der Lehrwerke im analysierten Zeitraum pro Verlag (n=1693) (eigene Tabelle)

\begin{tabular}{lccc}
\hline Verlage & $\begin{array}{c}\text { Durchschnitt } \\
\text { (Gramm) }\end{array}$ & $\begin{array}{c}\text { Anzahl der } \\
\text { Lehrwerke }\end{array}$ & $\begin{array}{c}\text { Abweichung } \\
\text { (Gramm) }\end{array}$ \\
\hline Apáczai & 232 & 63 & 83 \\
\hline Holnap & 216 & 11 & 131 \\
\hline Hueber (und ihre Rechtsvorgänger) & 467 & 400 & 152 \\
\hline Konsept-H & 254 & 14 & 53 \\
\hline Lexika & 336 & 89 & 50 \\
\hline Maxim & 510 & 83 & 194 \\
\hline Nemzedékek Tudása & 297 & 428 & 100 \\
(und ihre Rechtsvorgänger) & 309 & 24 & 87 \\
\hline Nordwest 2002 & 145 & 187 & 46 \\
\hline Oktatási Módszertani Kiadó & 350 & 9 & 0 \\
\hline Oxford University Press & 340 & 258 & 127 \\
\hline Raabe Klett (und ihre Rechtsvorgänger) & 343 & 2 & 0 \\
\hline SZEGA BOOKS & 224 & 125 & 129 \\
\hline ZIEL & $\mathbf{3 3 1}$ & $\mathbf{1 6 9 3}$ & $\mathbf{1 6 1}$ \\
\hline Zusammen & & &
\end{tabular}

Seit dem Schuljahr 2006/2007 enthalten die offiziellen Lehrbuchlisten Angaben über das Gewicht der Lehrwerke. Deshalb gibt es nur von 13 Verlagen solche Informationen in den analysierten Lehrbuchlisten. Das höchste Gewicht ist durchschnittlich bei Maxim (510 Gramme), es wird von Hueber (467 Gramme) gefolgt, dann Oktatási Módszertani Kiadó (350 Gramme). Die größten Abweichungen sind bei Maxim (194 Gramme), dann Hueber (152 Gramme) und Holnap (131 Gramme) zu sehen. Das Gewicht ist für die Schüler am wichtigsten, die 
nicht nur ein Buch in ihren Taschen haben, und wenn der Lehrer ein Mitglied einer Lehrbuchreihe gewählt hat, sollen die Schüler mit diesem Durchschnittgewicht in mehreren Schuljahren rechnen.

In den Lehrbuchlisten ist auch der empfohlene Schultyp seit dem Schuljahr 2006/2007 sehbar. Dazu sind hier einige Informationen über das ungarische Schulsystem. In Ungarn dauert die Bildung in der Grundschule acht Jahre lang und die Mittelschule (= Sekundarstufe II) vier oder fünf Jahre lang. Es gibt auch sechs- und achtjährige Gymnasien, dann dauert die Grundschule vorher sechs oder vier Jahre lang. Die Klassen sind während der Bildungszeit einheitlich von eins bis dreizehn nummeriert. In der Sekundarstufe II gibt es drei Schultypen: Gymnasium, Fachmittelschule und Fachschule. Es gibt noch die Schule für primären Kunstunterricht, dessen Name für sich spricht: die Schüler lernen verschiedene Kunstarten - zum Beispiel Musik. Der sonstige Schultyp bedeutet solche Lehrwerke, die man nicht zu einem Schultyp binden kann. Diese Lehrmittel können zum Beispiel bei der Vorbereitung auf eine Sprachprüfung oder das Abitur geeignet sein (Tabelle 5).

Tabelle 5. Die Anzahl der Lehrwerke in den einzelnen Schultypen ( $n=5217$ Erwähnungen) (eigene Tabelle)

\begin{tabular}{|c|c|c|c|c|c|c|c|c|}
\hline Verlag & $\begin{array}{l}\text { Grund- } \\
\text { schule }\end{array}$ & $\begin{array}{l}\text { 4-jährige } \\
\text { Gymn. }\end{array}$ & $\begin{array}{l}\text { 6-jährige } \\
\text { Gymn. }\end{array}$ & $\begin{array}{l}\text { 8-jährige } \\
\text { Gymn. }\end{array}$ & $\begin{array}{l}\text { Fach- } \\
\text { mittel- } \\
\text { schule }\end{array}$ & $\begin{array}{l}\text { Fach- } \\
\text { schule }\end{array}$ & $\begin{array}{l}\text { Schule für } \\
\text { primären } \\
\text { Kunst- } \\
\text { unterricht }\end{array}$ & Sonst. \\
\hline $\begin{array}{l}\text { Alfárium } \\
\text { Szuggesztopéd } \\
\text { Nyelvstúdió GM }\end{array}$ & 0 & 0 & 0 & 0 & 0 & 0 & 0 & 12 \\
\hline Apáczai & 65 & 0 & 0 & 0 & 0 & 0 & 0 & 17 \\
\hline $\begin{array}{l}\text { Baja és Tsa Oktatási } \\
\text { Bt. }\end{array}$ & 0 & 0 & 0 & 0 & 0 & 0 & 0 & 1 \\
\hline Corvina & 0 & 0 & 0 & 0 & 0 & 0 & 0 & 2 \\
\hline Holnap & 14 & 0 & 0 & 0 & 0 & 0 & 0 & 13 \\
\hline Homonnai és Társa & 0 & 0 & 0 & 0 & 0 & 0 & 0 & 2 \\
\hline $\begin{array}{l}\text { Hueber (und ihre } \\
\text { Rechtsvorgänger) }\end{array}$ & 88 & 18 & 20 & 188 & 102 & 0 & 0 & 180 \\
\hline Konsept-H & 14 & 0 & 0 & 0 & 0 & 0 & 0 & 3 \\
\hline Korona & 0 & 0 & 0 & 0 & 0 & 0 & 0 & 2 \\
\hline Könyvesház & 0 & 0 & 0 & 0 & 0 & 0 & 0 & 2 \\
\hline Langenscheidt & 0 & 0 & 0 & 0 & 0 & 0 & 0 & 6 \\
\hline Lexika & 14 & 18 & 42 & 15 & 10 & 0 & 0 & 65 \\
\hline Maxim & 0 & 0 & 83 & 0 & 0 & 0 & 0 & 0 \\
\hline Mozaik & 0 & 0 & 0 & 0 & 0 & 0 & 0 & 8 \\
\hline $\begin{array}{l}\text { Nemzedékek } \\
\text { Tudása (und ihre } \\
\text { Rechtsvorgänger) }\end{array}$ & 120 & 14 & 10 & 221 & 38 & 49 & 2 & 158 \\
\hline
\end{tabular}




\begin{tabular}{|c|c|c|c|c|c|c|c|c|}
\hline Verlag & $\begin{array}{l}\text { Grund- } \\
\text { schule }\end{array}$ & $\begin{array}{l}\text { 4-jährige } \\
\text { Gymn. }\end{array}$ & $\begin{array}{l}\text { 6-jährige } \\
\text { Gymn. }\end{array}$ & $\begin{array}{l}\text { 8-jährige } \\
\text { Gymn. }\end{array}$ & $\begin{array}{l}\text { Fach- } \\
\text { mittel- } \\
\text { schule }\end{array}$ & $\begin{array}{l}\text { Fach- } \\
\text { schule }\end{array}$ & $\begin{array}{c}\text { Schule für } \\
\text { primären } \\
\text { Kunst- } \\
\text { unterricht }\end{array}$ & Sonst. \\
\hline Nordwest 2002 & 0 & 0 & 0 & 24 & 0 & 0 & 0 & 0 \\
\hline $\begin{array}{l}\text { Oktatási } \\
\text { Módszertani Kiadó }\end{array}$ & 125 & 0 & 66 & 0 & 0 & 0 & 0 & 118 \\
\hline OKTKER (NODUS) & 0 & 0 & 0 & 0 & 0 & 0 & 0 & 1 \\
\hline $\begin{array}{l}\text { Oxford University } \\
\text { Press }\end{array}$ & 0 & 0 & 12 & 0 & 0 & 0 & 0 & 6 \\
\hline Paginarium & 0 & 0 & 0 & 0 & 0 & 0 & 0 & 1 \\
\hline Pedellus N. V. & 0 & 0 & 0 & 0 & 0 & 0 & 0 & 5 \\
\hline $\begin{array}{l}\text { Raabe Klett } \\
\text { (und ihre } \\
\text { Rechtsvorgänger) }\end{array}$ & 22 & 71 & 30 & 59 & 40 & 52 & 0 & 83 \\
\hline $\begin{array}{l}\text { Romi-Suli } \\
\text { Könyvkiadó és } \\
\text { Továbbképző } \\
\text { Műhely }\end{array}$ & 0 & 0 & 0 & 0 & 0 & 0 & 0 & 6 \\
\hline SZEGA BOOKS & 0 & 2 & 0 & 0 & 0 & 0 & 0 & 0 \\
\hline ZIEL & 54 & 5 & 15 & 0 & 0 & 0 & 0 & 121 \\
\hline Zusammen & 1062 & 883 & 1005 & 1054 & 868 & 271 & 37 & 37 \\
\hline
\end{tabular}

In dieser Tabelle lässt sich sehen, ob die Verlage ein Schultypprofil haben. Der Verlag Nemzedékek Tudása ist der Einzige, der Lehrbücher für alle Schultypen hat. Es gibt ein Verlag, Raabe Klett, der für jeden grund- und mittelstufigen Schultyp Lehrwerke „Deutsch als Fremdsprache“ herausgibt. Der Verlag Maxim hat Lehrwerke nur für das sechsjährige Gymnasium, Nordwest 2002 nur für das achtjährige Gymnasium und SZEGA BOOKS nur für das vierjährige Gymnasium. Die Verlage Hueber und Lexika haben Lehrwerke nur für die Grundschule, für alle Typen der Gymnasien sowie für die Fachmittelschule. Außer den Verlagen Maxim, Nordwest 2002 und SZEGA BOOKS haben alle anderen Verlage Lehrwerke für sonstige Ausbildungen. Das bedeutet solche Lehrwerke, die zum Beispiel die Vorbereitung auf eine Sprachprüfung oder auf das Abitur erleichtern können. Die Angaben zeigen, dass die Verlage im analysierten Zeitraum kein einheitliches Profil in Verbindung der Schultypen haben, wie es noch im Jahre 2000 der Fall war (Fehérvári 2000).

Ein Lehrwerk kann für mehrere Klassen nutzbar sein. Die Frage sind zum Beispiel: Für welche Klasse die meisten Lehrwerken entsprechend sind? Oder gibt es bestimmte Altersklassen, die die einzelnen Verlage bevorzugen (Tabelle 6)? 
Tabelle 6. Die Anzahl der Lehrwerke in den einzelnen Klassen (n=6182 Erwähnungen) (eigene Tabelle)

\begin{tabular}{|c|c|c|c|c|c|c|c|c|c|c|c|c|c|c|}
\hline Verlage & 1. & 2. & 3. & 4. & 5. & 6. & 7. & 8. & 9. & 10. & 11. & 12. & 13. & Sonst. \\
\hline $\begin{array}{l}\text { Alfárium Szuggesztopéd } \\
\text { Nyelvstúdió GM }\end{array}$ & 0 & 0 & 0 & 0 & 6 & 6 & 6 & 6 & 0 & 0 & 0 & 0 & 0 & 0 \\
\hline Apáczai & 15 & 12 & 11 & 12 & 6 & 7 & 6 & 10 & 0 & 0 & 0 & 0 & 0 & 0 \\
\hline Baja és Tsa Oktatási Bt. & 0 & 0 & 0 & 0 & 0 & 0 & 0 & 0 & 0 & 0 & 0 & 0 & 0 & 0 \\
\hline Corvina & 0 & 0 & 0 & 0 & 0 & 0 & 0 & 0 & 0 & 0 & 0 & 0 & 0 & 0 \\
\hline Holnap & 0 & 0 & 3 & 2 & 13 & 13 & 13 & 13 & 7 & 6 & 6 & 6 & 0 & 0 \\
\hline Homonnai és Társa & 0 & 0 & 0 & 0 & 0 & 0 & 0 & 0 & 0 & 1 & 0 & 0 & 0 & 0 \\
\hline $\begin{array}{l}\text { Hueber (und ihre } \\
\text { Rechtsvorgänger) } \\
\end{array}$ & 110 & 102 & 96 & 96 & 99 & 128 & 120 & 124 & 308 & 308 & 297 & 276 & 3 & 0 \\
\hline Konsept-H & 0 & 0 & 0 & 0 & 14 & 0 & 0 & 0 & 3 & 3 & 3 & 3 & 0 & 0 \\
\hline Korona & 0 & 0 & 0 & 0 & 0 & 0 & 0 & 0 & 0 & 0 & 0 & 0 & 0 & 0 \\
\hline Könyvesház & 1 & 1 & 1 & 1 & 1 & 1 & 0 & 0 & 0 & 0 & 0 & 0 & 0 & 0 \\
\hline Langenscheidt & 0 & 0 & 0 & 0 & 0 & 0 & 0 & 0 & 0 & 0 & 0 & 0 & 0 & 0 \\
\hline Lexika & 12 & 24 & 46 & 16 & 27 & 41 & 40 & 22 & 11 & 11 & 11 & 11 & 0 & 12 \\
\hline Maxim & 0 & 0 & 0 & 0 & 0 & 0 & 0 & 0 & 33 & 57 & 56 & 32 & 0 & 0 \\
\hline Mozaik & 0 & 0 & 0 & 0 & 0 & 0 & 0 & 0 & 6 & 6 & 6 & 6 & 0 & 0 \\
\hline $\begin{array}{l}\text { Nemzedékek Tudása (und } \\
\text { ihre Rechtsvorgänger) }\end{array}$ & 94 & 39 & 20 & 36 & 55 & 79 & 106 & 85 & 185 & 214 & 243 & 192 & 1 & 1 \\
\hline Nordwest 2002 & 0 & 0 & 0 & 0 & 0 & 0 & 0 & 0 & 0 & 0 & 24 & 24 & 0 & 0 \\
\hline $\begin{array}{l}\text { Oktatási Módszertani } \\
\text { Kiadó }\end{array}$ & 31 & 31 & 37 & 91 & 57 & 58 & 46 & 40 & 0 & 0 & 0 & 0 & 0 & 0 \\
\hline OKTKER (NODUS) & 0 & 0 & 0 & 0 & 0 & 0 & 0 & 0 & 0 & 0 & 0 & 0 & 0 & 0 \\
\hline Oxford University Press & 0 & 0 & 0 & 0 & 18 & 18 & 18 & 10 & 5 & 0 & 0 & 0 & 0 & 0 \\
\hline Paginarium & 0 & 0 & 0 & 0 & 0 & 0 & 0 & 0 & 0 & 0 & 0 & 0 & 0 & 0 \\
\hline Pedellus N. V. & 0 & 0 & 0 & 0 & 0 & 0 & 0 & 0 & 0 & 0 & 0 & 0 & 0 & 0 \\
\hline $\begin{array}{l}\text { Raabe Klett (und ihre } \\
\text { Rechtsvorgänger) }\end{array}$ & 88 & 19 & 30 & 57 & 78 & 67 & 96 & 96 & 191 & 195 & 189 & 188 & 0 & 7 \\
\hline $\begin{array}{l}\text { Romi-Suli Könyvkiadó és } \\
\text { Továbbképző Műhely }\end{array}$ & 0 & 6 & 0 & 0 & 0 & 0 & 0 & 0 & 0 & 0 & 0 & 0 & 0 & 0 \\
\hline SZEGA BOOKS & 2 & 0 & 0 & 0 & 0 & 0 & 0 & 0 & 2 & 1 & 1 & 0 & 0 & 0 \\
\hline ZIEL & 4 & 8 & 13 & 36 & 35 & 39 & 38 & 67 & 0 & 0 & 0 & 0 & 0 & 0 \\
\hline Zusammen & 357 & 242 & 257 & 347 & 409 & 457 & 489 & 473 & 751 & 802 & 836 & 738 & 4 & 20 \\
\hline
\end{tabular}

Die Verlage können mehrere Klassen pro Lehrwerk als empfehlenswert benennen. So sind in der Tabelle 66182 Antworten zusammen. Die meisten Lehrwerke sind für die elfte Klasse (836 Erwähnungen), zehnte Klasse (802 Erwähnungen) sowie neunte Klasse (751 Erwähnungen) geeignet. Es gibt 20 Lehrwerke, die nicht streng zu einer Klasse gehören, sondern diese Lehrwerke zum Beispiel bei der Vorbereitung auf die Sprachprüfung oder auf das Abitur helfen. Die Zahlen zeigen auch ein Profil der Verlage. Zum Beispiel hat der Verlag Apáczai im analysierten Zeitraum Lehrwerke nur bis zu der siebten Klasse, und dieser Verlag 
hat die meisten Lehrwerke für die erste Klasse. Der Verlag Holnap hat Lehrwerke für mehrere Jahrgänge, aber der hat die Meisten von der fünften bis zur achten Klasse. Ähnlich ist die Lage mit dem Verlag Oxford University Press oder ZIEL. Der Verlag Hueber und Nemzedékek Tudása haben für alle Jahrgänge mindestens ein Lehrwerk. Der Vorige hat die meisten Lehrwerke für die neunte und zehnte Klasse, aber der Andere hat Lehrmittel eher für die zehnte und elfte Klasse. Die folgenden Verlage haben Lehrwerke nur für die Sekundarstufe II: Homonnai és Társa, Maxim und Mozaik.

\section{Zusammenfassung}

Dieser Aufsatz handelt sich um die Datenanalyse der Lehrwerke „Deutsch als Fremdsprache”. Diese Daten stammen aus den offiziellen Lehrbuchlisten der letzten 17 Jahren. Die Analyse enthält mehrere Gesichtspunkte: die Anzahl der Lehrwerke „Deutsch als Fremdsprache“ in den einzelnen Schuljahren, die Anzahl der Verlage während dieser 17 Jahre, die vermutliche Muttersprache der Lehrwerkautoren, die Satellitenanzahl der Lehrwerke pro Verlag, den Preis der Lehrwerke pro Verlag, das durchschnittliche Gewicht der Lehrwerke pro Verlag, bzw. dass die einzelne Verlage in welchen Schultypen sowie an welchem Jahrgang die meisten eigenen Lehrwerke empfehlen. Aus den Angaben ergeben sich mehrere interessante Tatsachen.

Zum Beispiel war eine Verminderung der Anzahl der Lehrwerke „Deutsch als Fremdsprache“ seit dem Schuljahr 1998/1999 bis zu dem Schuljahr 2001/2002 und es wurde zuerst eine leichte, dann eine noch strengere Zunahme dieser Anzahl gewesen. Diese Veränderungen kann man mit den rechtlichen Veränderungen sowie mit der Wirtschaftskrise erklären. Es gibt während des analysierten Zeitraums insgesamt 25 Verlage in Ungarn, die mindestens ein Lehrwerk „Deutsch als Fremdsprache“ herausgegeben haben. Unter diesen 25 Verlagen gibt es drei, die auch Rechtsvorgänger hatten: Hueber, Nemzedékek Tudása und Raabe Klett. 24 Prozent der 25 Verlage arbeiten mit vermutlichen deutschmuttersprachigen Lehrwerkautoren zusammen. Das bedeutet, die Mehrheit der Verlage beschäftigt sich mit den regionalen Lehrwerken in Ungarn. Die 73,68 Prozent der Lehrwerke haben in der Lehrbuchliste irgendeine Satelliten. Es kann ein selbständiges Stück in der Lehrbuchliste sein, oder nur eine Verlagskode. Die Verlage Hueber, Nemzedékek Tudása und Raabe Klett haben die meisten Lehrbuchsatelliten pro Verlag und auch pro Lehrbücher. Diese Daten sind geeignet zu einer weiteren Analyse zum Beispiel mit den ungarischen Lehrwerken von anderen Fremdsprachen oder die Lage der Lehrwerke „Deutsch als Fremdsprache“ im Ausland.

Die Veränderung der Preise und des Gewichts bei den Verlagen und Lehrwerken scheint auch interessant zu sein. Im analysierten Zeitraum waren die Lehr- 
werke von Verlagen Konsept-H, Hueber und Oxford University Press im Durchschnitt die teuersten. Nicht nur die ausländischen Verlage haben teurere Lehrwerke, es gibt unter den ungarischen Verlagen auch hohe Preise zum Beispiel bei Nordwest 2002 oder SZEGA BOOKS. Während der 17 Jahre haben die folgenden Verlage die größten Abweichungen in den Preisen: Maxim, Kosept-H und Hueber. Die Veränderungen der Preise sind nur durchschnittlich, aber man kann darunter einige Tendenzen entdecken. In Verbindung mit dem höchsten Gewicht haben die folgenden Verlage die im Durchschnitt schwersten Lehrwerke: Maxim, Hueber, Oktatási Módszertani Kiadó. Die größten Abweichungen gibt es unter den Lehrwerken von Maxim, Hueber und Holnap. Das Gewicht der Schulbücher scheint für die Schüler am wichtigsten azu sein.

An den Lehrbuchlisten kann man auch Empfehlungen für den Schultyp und Jahrgang sehen. Der Verlag Nemzedékek Tudása hat für jeden Schultyp sowie jeden Jahrgang Lehrwerke, und nur der Verlag Hueber hat Lehrwerke für jeden Jahrgang. Die anderen Verlage haben spezifisches Angebot für die Jahrgänge, aber man kann kein solches spezifisches Angebot bei den Schultypen entdecken (vgl. Fehérvári 2000).

Zusammenfassend lässt sich sagen, dass die größten Verlage Hueber, Nemzedékek Tudása sowie Raabe Klett sind. Unter den populärsten Verlage war der Nemzeti Tankönyvkiadó - der Rechtsvorgänger des Verlags Nemzedékek Tudása - schon auch 1998 sehr bekannt, dagegen waren die anderen zwei Verlage noch nicht so berühmt. Im Jahre 1998 waren auch die Verlage Apáczai, Korona, Mozaik bekannt, und diese Verlage existieren auch heutzutage, aber ihr Angebot ist nicht so groß und populär wie früher (Karlovitz J. T. 2001). Diese Daten und Fakten der Verlage und Lehrwerke können in der Zukunft nicht nur in Ungarn, sondern auch im Ausland noch zu weiteren Forschungen führen.

\section{Literaturverzeichnis}

5/1998. (II.18.) MKM rendelet a tankönyvvé nyilvánítás, a tankönyvtámogatás, valamint az iskolai tankönyvellátás rendjéről. [Verordnung MKM über die Ordnung der Lehrbuchbestimmung, Lehrbuchunterstützung, sowie Lehrbuchversorgung.]

2001. évi XXXVII. törvény a tankönyvpiac rendjéről. [Gesetz über die Ordnung des Lehrbuchmarkts.]

23/2004 (VIII. 27.) OM rendelet a tankönyvvé nyilvánítás, a tankönyvtámogatás, valamint az iskolai tankönyvellátás rendjéről. [Verordnung OM über die Lehrbuchzulassung, Lehrbuchunterstützung beziehungsweise die Lehrbuchversorgung der Schulen.] 
237/2006. (XI. 27.) Korm. Rendelet a felsőoktatási intézmények felvételi eljárásairól. [Verordnung über das Aufnahmsverfahren der Hochschulen.]

2011. évi CXC törvény a nemzeti köznevelésről. [Nationales Erziehungsgesetz.]

2013. CCXXXII. törvény a nemzeti köznevelés tankönyvellátásáról. [Gesetz über die nationale Lehrbuchverbreitung].

17/2014. (III. 12.) EMMI rendelet a tankönyvvé, pedagógus kézikönyvvé nyilvánítás, a tankönyvtámogatás, valamint az iskolai tankönyvellátás rendjéről. [Verordnung EMMI über die Ordnung Lehrbuchbestimmung, Lehrerhandbuchbestimmung, Lehrbuchunterstützung sowie Lehrbuchversorgung.]

Fábián, Gyöngyi. 2003. A nyelvtanári szerep alakító tényezői. Az elvárások. [Die Gestaltungsfaktoren der Rolle von Fremdsprachenlehrern. Die Erwartungen.]. In: Kiss, Endre-Lénárd, Gábor. (Hrsg.): Interdiszciplináris pedagógia és a tudás társadalma. A II. Kiss Árpád Emlékkonferencia előadásai. Debrecen 2001. november. Debrecen: Kiss Árpád Archívum Könyvtára - Debreceni Egyetem Neveléstudományi Tanszék, 556-567.

Fehér könyv 2012-2018. A nemzeti idegennyelv-oktatás fejlesztésének stratégiája az általános iskolától a diplomáig. Melléklet a 49545-2/2012. számú elöterjesztéshez. [Weißes Buch 2012-2018. Die Entwicklungsstrategie des nationalen Fremdsprachenunterrichts von der Grundschule bis das Diplom. Beilage zur Vorlage 49545-2/2012] http://nyelvtudasert.hu/cms/data/uploads/ idegennyelv-oktatas-feher-konyv.pdf (14. Oktober 2015)

Fehérvári, Anikó. 2000. Tankönyvrendelés. [Schulbuchbestellung.] Educatio, 9 (3). 460-473.

Gerighausen, Josef-Seel, Peter C. 1982. Regionale Lehrwerke. In: Krumm, HansJürgen (Hrsg.): Lehrwerkforschung. Lehrwerkkritik Deutsch als Fremdsprache. Protokoll eines Werkstattgesprächs der Fachgruppe Deutsch als Fremdsprache (Fachwerkband Moderne Fremdsprache) in Zusammenarbeit mit dem Goethe-Institut in München vom 23. bis 24. Oktober 1981. München: Kemmler \& Hoch, 23-35.

Hesse, Hermann-Günter-Kerstin Göbel-Johannes Hartig. 2008. Sprachliche Kompetenzen von mehrsprachigen Jugendlichen nicht-deutscher Erstsprache. In: Klieme, Eckhard (Hrsg.): Unterricht und Kompetenzerwerb in Deutsch und Englisch. Ergebnisse der DESI-Studie. Weinheim u. a.: Beltz, 208-230.

Imre, Anna. 2015. Tanulmányi és tapasztalatszerzési utak pályakezdők körében. [Lern- und Erfahrungserwerbswege unter den Berufsanfängern.] In: Pusztai, Gabriella-Kovács, Klára (Hrsg.): Ki eredményes a felsőoktatásban? NagyváradBudapest: Partium Press-Új Mandátum, 215-232. (= Felsőoktatás és Társadalom 1.)

Karlovitz, János. 2001. Tankönyv. Elmélet és gyakorlat. [Lehrbuch. Theorie und Praxis.] Budapest: Nemzeti Tankönyvkiadó. 
Karlovitz, János Tibor. 2001. Az iskolai tankönyvválasztásról. [Über die schulischen Lehrbuchauswahl.] Új Pedagógiai Szemle, 51 (1). 69-79.

Kommission der Europäischen Gemeinschaften. 2005. Mitteilung der Kommission an das europäische Parlament und den Rat: Europäischer Indikator für Sprachenkompetenz. Brüssel: Kommission der Europäischen Gemeinschaften.

Petneki, Katalin. 2002. Az idegen nyelv tanításának helyzete és fejlesztési feladatai. [Die Lage der Fremdsprachenunterricht und ihre Entwicklungsaufgaben.] Új Pedagógiai Szemle, 52 (7-8). 147-160.

Pingel, Falk. 2010. UNESCO Guidebook on Textbook Research and Textbook Revision. $2^{\text {nd }}$ revised and updated edition. Paris-Braunschweig: UNESCO-Georg Eckert Institute for International Textbook Research.

Radó, Péter. 2010. Tankönyvpiac és tankönyvpolitika Magyarországon. Összefoglaló tanulmány. [Lehrbuchmarkt und Lehrbuchpolitik in Ungarn. Zusammenfassender Aufsatz.] Budapest: Expanzió Humán Tanácsadó.

Sebestyén, Krisztina. 2014. Miről olvasunk a sorok között? - A május-júniusi német nyelvi, emelt szintû, jeles érettségi vizsgák eredményeinek elemzése 2006-2013. [Analyse der Ergebnissen von den oberen Stufe des Abiturs, die zwischen 2006 und 2013 ausgezeichnet wurden.] Csiszár, Imre und Kőmíves, Péter Miklós. Hrsg. Tavaszi Szél / Spring Wind 2014 Konferenciakötet. IV. kötet: Szociológia és multidiszciplináris társadalomtudomány, pszichológia és neveléstudomány, hittudomány. Debrecen: Doktoranduszok Országos Szövetsége, 403-410.

Szablyár, Anna. 1995. Zur Problematik der regionalen Lehrbücher des Deutschen in Ungarn. In: Mádl, Antal-Wolfgang Schmitt (Hrsg.): Jahrbuch der ungarischen Germanistik. Budapest: Gesellschaft der Ungarischen Germanisten Bonn: Deutsche Akademischer Austauschdienst, 179-192.

Vágó, Irén-Simon, Mária-Vass, Vilmos. 2011. Hagyományos és új tartalomhordozók. [Traditionelle und neue Inhaltsträger.] In: Balázs, Éva-Kocsis, Mihály-Vágó, Irén (Hrsg.): Jelentés a magyar közoktatásról 2010. Budapest: Oktatáskutató és Fejlesztő Intézet, 262-272.

Zalánné Szablyár, Anna-Petneki, Katalin. 1997. Hogyan válasszunk nyelvkönyvet? [Wie wählen wir ein Fremdsprachenbuch?] Budapest: Soros Alapítvány. (= Soros oktatási füzetek) 


\section{Die offiziellen Lehrbuchlisten}

A közoktatás nyelvkönyvei. 1998/99. tanév. [Die Sprachbücher der Bildung. Schuljahr 1998/1999.] [1998]. Budapest: Múvelődési és Közoktatási Minisztérium, 26-36.

Tankönyvjegyzék 1999/2000. Élő idegen nyelv - A közoktatás tankönyvei. [Lehrbuchliste 1999/2000. Lebende Fremdsprache - Die Sprachbücher der Bildung.] 1999. Budapest: Oktatási Minisztérium, 107-124, 348.

Közoktatási tankönyvjegyzék 2000/2001. tanév. [Lehrbuchliste des Schuljahrs 2000/2001.] 2000. Budapest: Oktatási Minisztérium, 231-251.

Közoktatási Tankönyvjegyzék 2001/2002. [Lehrbuchliste 2001/2002.] 2000. Budapest: Oktatási Minisztérium. 221-225.

Közoktatási tankönyvjegyzék, tájékoztató a tankönyvrendelésról és a kiadókról 2002-2003. tanév. [Lehrbuchliste, Aufklärung über die Bestellung der Lehrbücher und über die Verlage 2002/2003.] 2001. Budapest: Oktatási Minisztérium, 236-242.

Közoktatási tankönyvjegyzék a 2003-2004-es tanévre. [Lehrbuchliste des Schuljahrs 2003/2004.] 2002. Budapest: Oktatási Minisztérium, 238-244.

Közoktatási tankönyvjegyzék a 2004-2005-ös tanévre. [Lehrbuchliste des Schuljahrs 2004/2005.] 2003. Oktatási Közlöny Nr. 36/II. 5312-5317.

Közoktatási tankönyvjegyzék a 2005-2006. tanévre. [Lehrbuchliste des Schuljahrs 2005/2006.] 2004. Oktatási Közlöny Nr. 35/III. 4908-4922.

Közoktatási tankönyvjegyzék a 2006-2007. tanévre. [Lehrbuchliste des Schuljahrs 2006/2007.] 2006. Oktatási Közlöny. Az oktatási minisztérium hivatalos lapja vol. XLIX. Nr. 36/III. 31. Dezember 2005. 413-436.

A 2007-2008. tanévi közoktatási tankönyvjegyzék. [Lehrbuchliste des Schuljahrs 2007/2008.] 2007.

http://www.nefmi.gov.hu/site/tankonyvjegyzek/archivum/2007.12/kozokttankonyvjegyzek20071220.pdf 413-436. (23. Januar 2015)

A 2008-2009. tanévi közoktatási tankönyvjegyzék. [Lehrbuchliste des Schuljahrs 2008/2009.] 2008.

http://www.nefmi.gov.hu/site/tankonyvjegyzek/archivum/2008.10/kozokttankonyvjegyzek20081018.pdf (23. Januar 2015)

A 2009-2010. tanévi közoktatási tankönyvjegyzék. [Lehrbuchliste des Schuljahrs 2009/2010.] 2009.

http://www.nefmi.gov.hu/site/tankonyvjegyzek/archivum/2009.10/kozokttankonyvjegyzek20091015.pdf (23. Januar 2015)

A 2010-2011. tanévi közoktatási tankönyvjegyzék. [Lehrbuchliste des Schuljahrs 2010/2011.] 2010.

http://www.nefmi.gov.hu/tankonyvjegyzek/archivum/2010.11/kozokttankonyvjegyzek20101111.pdf (23. Januar 2015) 
A 2011-2012. tanévi közoktatási tankönyvjegyzék. [Lehrbuchliste des Schuljahrs 2011/2012.] 2011.

http://www.nefmi.gov.hu/tankonyvjegyzek/aktualis/kozokttankonyvjegyzek. pdf (23. Januar 2015)

A 2012-2013. tanévi közoktatási tankönyvjegyzék. [Lehrbuchliste des Schuljahrs 2012/2013.] 2012.

http://files.szello.webnode.hu/200000027-0d2f80e28b/TANK\%C3\% 96NYVJEGYZ\%C3\% 89K\% 202012-13.pdf (23. Januar 2015)

A 2013-2014. tanévi közoktatási tankönyvjegyzék. [Lehrbuchliste des Schuljahrs 2013/2014.] 2013. http://www.oktatas.hu/pub_bin/dload/kozoktatas/tankonyvjegyzek/kirtkv2013_kozlony130304.pdf (04. Oktober 2015)

A 2014-2015. tanévi közoktatási tankönyvjegyzék. [Lehrbuchliste des Schuljahrs 2014/2015.] 2014.

http://www.oktatas.hu/pub_bin/dload/kozoktatas/tankonyvjegyzek/ kirtkv2014_kozlony_141106.pdf (23. Januar 2015) 